Weckx, S.; Driesen, J., "Load Balancing With EV Chargers and PV Inverters in Unbalanced Distribution Grids," Sustainable Energy, IEEE Transactions on , vol.PP, no.99, pp.1,18

Digital Object Identifier: 10.1109/TSTE.2015.2402834

URL: $\underline{\text { http://ieeexplore.ieee.org/stamp/stamp.jsp?tp=\&arnumber=7057546\&isnumber }=5433168}$

IEEE. Personal use of this material is permitted. Permission from IEEE must be obtained for all other users, including reprinting/ republishing this material for advertising or promotional purposes, creating new collective works for resale or redistribution to servers or lists, or reuse of any copyrighted components of this work in other works. 


\title{
Load Balancing with EV chargers and PV inverters in Unbalanced Distribution Grids
}

\author{
Sam Weckx, Student Member, IEEE, Johan Driesen, Senior Member, IEEE
}

\begin{abstract}
Balanced three-phase four-wire distribution grids can host significantly more distributed generation and electric vehicles. Three-phase $P V$ inverters and $E V$ chargers can be adapted to transfer power from highly loaded to less loaded phases, without overloading the inverter or charger. Grid conditions will be improved due to a more balanced operation of the network and more PV panels and EVs can be connected before the limits of the network are reached.

A classic coordinated charging strategy for EVs is adapted in this paper. It is shown that the charging of EVs can be improved when power can be transferred from one phase to another. By using PV inverters with a balancing inverter the power injected in each phase will become a controllable variable, as the total amount of produced power does not necessarily need to be equally divided across the three phases. The improvements made by using EV chargers and PV inverters that can balance the network are investigated. Several load flow simulations with realistic data show a positive effect on the system losses, the grid voltage and voltage unbalance. Finally a local controller is proposed to control the balancing between the phases when a real-time communication channel is not available.
\end{abstract}

Index Terms-Coordinated charging, distributed generation, electric vehicles, load balancing, power quality, valley-filling, voltage control

\section{INTRODUCTION}

A high penetration of distributed photovoltaic generators $(\mathrm{PV})$ and electric vehicles (EVs) may lead to power quality problems in low-voltage (LV) distribution networks. European LV distribution networks are often of the three-phase fourwire type. Both PVs and EVs are often not equally spread across the three phases of the distribution network which will increase the load unbalance [1]-[5]. An unbalanced operation of the network will result in a serious increase in the system losses, voltage problems and voltage unbalance. Furthermore an unbalanced network can host less PV generation before the critical voltage limit is reached. PVs can extend the transformer life [6], but a high amount of EVs will decrease it.

Different approaches are proposed to balance the load in the three phases. A first solution for the Distribution System Operator (DSO) is manually switching the phase to improve the distribution of the load across the three phases [7]. This can become very costly and the more switching actions, the higher the cost for the DSO. An alternative is dynamically

S. Weckx is with ELECTA, KU Leuven, Kasteelpark Arenberg 10, bus 2445, 3001 Leuven, Belgium and with VITO, Boerentang 200 Mol, Belgium. $\mathrm{He}$ has a PhD fellowship of the Research Foundation Flanders (FWO-VITO). J. Driesen is with ELECTA, KU Leuven, Kasteelpark Arenberg 10, bus 2445, 3001 Leuven, Belgium. VITO and ELECTA are members of the Energyville research institute.

Corresponding author's email address: sam.weckx@esat.kuleuven.be switching residential load from one phase to another [8], [9]. This requires the use of static transfer switches. In [10] a droop control for negative sequence currents is proposed. [11] develops a control scheme for a three-phase four-wire inverter to deliver negative sequence currents based on measurements of the negative sequence voltage. Another approach is applied in [12], where the inverter has a resistive behaviour towards the zero-sequence and negative-sequence component of the node voltage. Most of the work described in literature is focused on the control schemes of inverters capable of providing negative- and zero-sequence currents [13]-[15]. This work is focussed on the effect that optimally controlling these balancing inverters has on the network.

Many central and local control strategies have been described in literature where EVs [16]-[23] or PVs [24]-[28] are controlled to improve the power quality in distribution grids. Types of control are reactive power compensation, active power curtailment, disconnecting PV, and coordinated charging of EVs. Reactive power compensation can require additional inverter capacity [29] and might increase grid losses. Active power curtailment of PV panels will result in a lower amount of energy produced and a lower revenue for their owners. EV charging power curtailment can reduce the voltage drop caused by the charging of EVs, but can lead to an unwanted extension of the charging time [30]. Disconnecting PV units in case of a voltage violation can lead to a cascade of disconnections [31]. In [32], [33] a battery energy storage system is controlled to limit the voltage deviations caused by PV production. Some of these methods are applied to unbalanced three-phase four-wire grids, but none of these control strategies consider the possibility to transfer power from one phase to another by means of an EV charger or PV inverter.

By replacing classical single-phase or three-phase PV units by three-phase balancing PV units that are able to inject more power in one phase than in the other phases, the total power can be more equally spread across the three phases. The majority of houses have a single-phase power supply but larger houses may have three-phase connections [8], [34]. In the houses with a three-phase connection a balancing charger or inverter can be installed. Solar cells rarely produce maximal power and therefore it is often possible to inject the majority of the generated power into the phase with the highest power consumption, without overloading of the inverter. Similarly, EVs are only charged for a limited time during the day, so an off board charger capable of balancing the network can be used extensively for this purpose. In this work a charger or inverter with six inverter legs is used as an alternative to standard threephase units for the connection of three-phase PV or EV units 
to the distribution network. This inverter can be interpreted as three single-phase inverters with a common DC-bus. Special care is required for the DC-bus voltage control [11]. The use of three separate single-phase inverters is often already more interesting for PV units than the use of one three-phase inverter, due to disconnection regulations [35]. If the voltage rises above a certain threshold, typically $+10 \%$, the inverter has to disconnect. If three separate single-phase inverters are used, only the inverter connected to the overloaded phase has to disconnect. This results in lower amounts of curtailed energy. The higher possible charging power can make the three-phase charger interesting for an EV owner.

The inverters and chargers will be controlled to balance the load in the three phases. By transferring power from highly loaded to less loaded phases, system conditions will be improved. A simplified representation of the working of a balancing inverter during the day and the night is presented in Fig. 1. The width of the arrows represents the amount of active power flowing through the connection. In previous work we introduced this concept for three-phase PV inverters [36].

PV inverters will mainly improve the grid conditions in the evening. In the evening, when no PV power is generated and high peak loads occur, full inverter capacity can be used to balance the grid. Power extracted from a phase with a low consumption can be injected into a phase with a high consumption. On the other hand, balancing off board EV chargers will improve the grid conditions mainly during the day, as the EV will often be absent during this time. Therefore both types of balancing are complementary.

Our first contribution is the adaptation of a coordinated charging formulation for EVs that includes the possibility to balance the grid with EV chargers. Secondly balancing PV inverters are added in this formulation. Several load flow simulations with realistic data show a significant improvement of the network conditions. Finally a local control approach is proposed. This avoids the need to have a real-time communication channel.

This paper is structured as follows: the distribution grid used in the simulation results is described in Section II. In Section III, a coordinated charging problem of EVs with grid balancers is presented. Finally, the local control rule is described in Section IV.
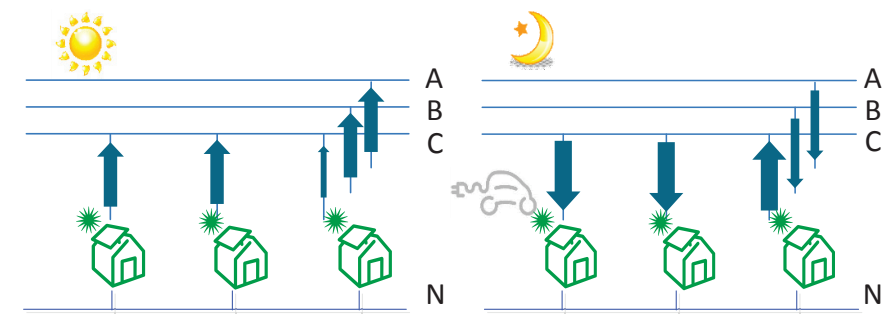

Fig. 1: Simplified representation of the working of the balancing inverter during the day and the night. At night power is extracted from phase A and B and is injected into the highly loaded phase $\mathrm{C}$.
TABLE I: Properties of the simulated network

\begin{tabular}{l|r|l} 
Properties & Value & Unit \\
\hline \hline Total feeder length & 1657 & {$[\mathrm{~m}]$} \\
Impedance of EAXVB $1 \mathrm{kV} 4 \times 95 \mathrm{~mm}^{2}$ & $0.352+0.078 \mathrm{j}$ & {$[\Omega / \mathrm{km}]$} \\
Impedance of EAXVB $1 \mathrm{kV} 4 \times 150 \mathrm{~mm}^{2}$ & $0.227+0.078 \mathrm{j}$ & {$[\Omega / \mathrm{km}]$}
\end{tabular}

\section{Simulated NETWORK}

The network used in the simulations is a typical Belgian low-voltage network provided by the DSO and is presented in Fig 2. The network is a three-phase, four-wire, radial system. Cable properties are defined in table I. The impedance values are calculated according to design specifications in the Belgian standard for underground distribution cables NBN C33-322 [37] with an assumed operating temperature of $45^{\circ} \mathrm{C} .62$ statistically representative residential load profiles were available to perform load flow simulations. A constant power load model was assumed. Generation of these load profiles is described in [38]. In [38] the privacy problem of data provided by electrical companies is bypassed by transforming a large dataset of residential load profiles into a model that is able to create a set of synthetic nonaggregated load profiles. This model was trained based on a large database of measured residential load profiles provided by the DSOs in Flanders. Reactive power consumption data was not available and therefore all loads are assumed to have a $\cos (\phi)$ equal to 0.95 . Load profiles were assigned randomly to households. Every house is equipped with a PV generator. The average power rating of PV units connected to phase A and B equals $2.2 \mathrm{~kW}$, while PV units connected to phase $\mathrm{C}$ have an average rating of $3.3 \mathrm{~kW}$. The PV profile was measured at a fixed rooftop PV installation at $\mathrm{KU}$ Leuven. The PV profile was scaled to the inverter size. All PV panels are assumed to have equal orientation. As the geographical area was small, the power output of all PV installations relative to their rated capacity was considered to be equal. Nodes 40 and 62 are equipped with a three-phase balancing inverter. The rated capacity of the three-phase PV installations is $6 \mathrm{~kW}$.

Each household with an odd number has an EV. The maximum charging power equals $3.3 \mathrm{~kW}$. Households 51 and 57 have an off board three-phase charger with a maximum charging power of $6.6 \mathrm{~kW}$. The EV driving behavior is based on a statistical availability model [39]. This model uses statistical data on Flemish transportation behavior, to create a realistic driving pattern for each vehicle. The voltage at the primary side of the transformer was assumed to be constant and equal to $1 \mathrm{pu}$. The nominal line-to-neutral voltage is $230 \mathrm{~V}$. Distribution grid conditions are calculated with a backwardforward sweep algorithm [40] and a time resolution of 15 minutes.

\section{COORDINATED CHARGING OF EVS WITH LOAD BALANCING BY PV INVERTERS AND EV CHARGERS}

A popular coordinated charging scheme for EVs is the minimization of load variance, also called valley filling [41]-[44]. The minimization of the load variance leads to low system losses and generally avoids the violation of the lower voltage 


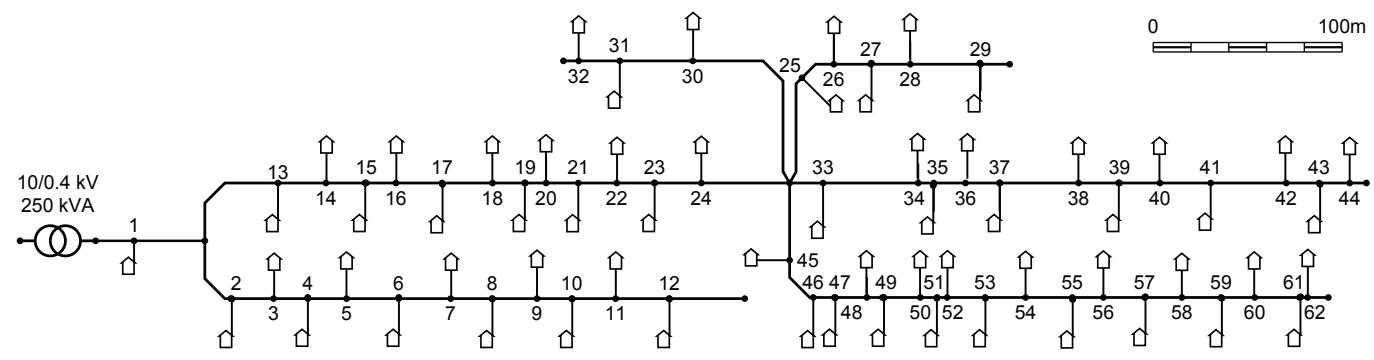

Fig. 2: The network used in the simulations. All lengths are drawn to scale.

limitations [41]. It is an easy to solve convex optimization problem [45].

This work is focussed on three-phase four-wire networks. These networks require special care when minimizing the load variance. If the variance of the sum of all phases would be minimized, load peaks might still exist on each phase separately. This can result in severe voltage drops in the phase with the highest loading and will increase the system losses. It is therefore recommended to minimize the sum of the load variances of each phase, which will result in a more equal loading of the three phases. The following three-phase formulation is preferred:

$$
\begin{array}{ll}
\min _{P^{\mathrm{EV}}} & \sum_{t=1}^{T} \sum_{i \in\{A, B, C\}}\left(\sum_{n=1}^{N}\left(P_{n, i, t}^{\mathrm{load}}+P_{n, i, t}^{\mathrm{PV}}+P_{n, i, t}^{\mathrm{EV}}\right)\right)^{2} \\
\text { subject to } & C_{n, t+1}=C_{n, t}+\eta_{n} \sum_{i \in\{A, B, C\}} P_{n, i, t}^{\mathrm{EV}} \Delta t \\
& 0 \leq C_{n, t} \leq C_{n}^{\max } \\
& C_{n, \text { tdparture }^{\text {de }}}=C_{n}^{\max }
\end{array}
$$

Where

- $P_{n, i, t}^{\text {load }}$ is the consumed power, excluding the EV, by the household connected at node $n$ to phase $i$ at time step $t$;

- $P_{n, i, t}^{\mathrm{PV}}$ is the generated power of the PV unit connected at node $n$ to phase $i$ at time step $t$;

- $P_{n, i, t}^{\mathrm{EV}}$ is the charging power of the EV connected at node $n$ to phase $i$ at time step $t$;

- $C_{n, t}$ is the stored energy in the EV connected at node $n$ at time step $t$;

- $C_{n}^{\max }$ is the maximal stored energy of the EV connected at node $n$;

- $\eta_{n}$ is the charging efficiency of the EV connected at node $n$;

For single-phase EV chargers energy can only be extracted from the phase of connection $k$ :

$$
\begin{aligned}
& \text { if } i=k \\
& 0 \leq P_{n, i, t}^{\mathrm{EV}} \leq P_{n}^{\mathrm{EV}, \text { max }} \\
& \text { else } \\
& P_{n, i, t}^{\mathrm{EV}}=0
\end{aligned}
$$

where $P_{n}^{\mathrm{EV} \text {,max }}$ is the maximal charging power of the EV connected at node $n$. In case of a three-phase EV charger capable of balancing the network, the energy can be extracted from each phase. The net energy exchange is constrained to be positive, but the power exchanged with one of the phases can be negative:

$$
0 \leq \sum_{i \in\{A, B, C\}} P_{n, i, t}^{\mathrm{EV}} \leq P_{n}^{\mathrm{EV}, \max }
$$

Besides that, the limits of the three single-phase inverters, out of which the balancing off board charger consists, need to be respected:

$$
-\frac{P_{n}^{\mathrm{EV}, \max }}{3} \leq P_{n, i, t}^{\mathrm{EV}} \leq \frac{P_{n}^{\mathrm{EV}, \max }}{3}
$$

It is assumed that the three single-phase inverters all have an identical rating of $\frac{1}{3}$ of the total charger rating $P_{n}^{\mathrm{EV} \text {,max }}$.

In a classic coordinated charging algorithm, the off board three-phase charger is unable to balance the network and the charging power in each phase needs to be equal:

$$
P_{n, A, t}^{\mathrm{EV}}=P_{n, B, t}^{\mathrm{EV}}=P_{n, C, t}^{\mathrm{EV}}
$$

Typically the PV production is an uncontrollable variable. The power injected in the network for a single-phase PV panel is therefore fixed. In case of a three-phase inverter capable of balancing, the power injected in each phase becomes a variable that can be controlled in optimization problem (1). The sum of the power injected in each phase should then equal the total power production and the limitations of the three single-phase inverters, out of which the balancing three-phase inverter is composed, need to be respected:

$$
\begin{aligned}
& \sum_{i \in\{A, B, C\}} P_{n, i, t}^{\mathrm{PV}}=P_{n, t}^{\mathrm{PV}} \\
& -\frac{P_{n}^{\mathrm{PV}, \max }}{3} \leq P_{n, i, t}^{\mathrm{PV}} \leq \frac{P_{n}^{\mathrm{PV}, \max }}{3}
\end{aligned}
$$

where $P_{n, t}^{\mathrm{PV}}$ is the total produced power by the PV panel at time step $t$ and $P_{n}^{\mathrm{PV} \text {,max }}$ is the rating of the balancing three-phase inverter connected at node $n$. Note that at night, when $P_{n}^{\mathrm{PV}}$ equals zero, the full inverter rating can be used to balance the grid.

The strict majority of the time, the off board EV charger will be able to balance the grid, as the maximum charging capacity will rarely be used to meet the required amount of energy by the time of departure of the EV owner. This depends on the driving pattern of the EV owner.

The full capacity of each of the single-phase inverters of a balancing PV inverter will only be used when the solar 
irradiation is optimal. This occurs for only a fraction of the year, so the majority of the time the PV inverter can balance the grid.

Optimization problem (1) with additional constraints (2-6) is an easy to solve quadratic program [45]. By solving this problem the charging profiles for all EVs are defined, as well as the setpoints of the balancing chargers and inverters. In this work CPLEX [46] is applied to solve this problem.

An equal loading of the three phases is beneficial for the voltages in the network. When power is transferred from the highest loaded phase, to the one with the lowest loading, the voltage drop in this phase will reduce. A special effect, called neutral point shifting [47], [48], occurs in three-phase fourwire distribution grids. When power is consumed in one phase, it will result in a voltage drop in this phase, but in a voltage increase in the two other phases. Therefore, the increased power consumption in the phase with the lowest loading will lead to a further improvement of the voltage of the phase with the highest loading. Balanced networks are therefore able to host significantly more PV and EVs.

In this work reactive power compensation is not considered. It can require additional inverter capacity [29] and might increase grid losses. Therefore, the proposed control will try to use the full inverter and charger capacity for balancing the active power consumption in each of the phases of the threephase four-wire distribution network.

The coordinated charging problem is tested on the network discussed in Section II. Fig. 3 shows the total active power in each of the three phases $\left(\sum_{n=1}^{N}\left(P_{n, i, t}^{\text {load }}+P_{n, i, t}^{\mathrm{PV}}+P_{n, i, t}^{\mathrm{EV}}\right)\right)$ for a period of two days during the summer. A negative value indicates a reverse power flow, which occurs when there is a higher PV production than consumption in this phase. When there is more consumption than production, the total active power in a phase will be positive. Compared to the case of uncoordinated charging, the load peaks are diminished. However due to the typical mismatch between PV production and the energy required by the EVs, the classic coordinated charging can only slightly reduce the maximum reverse power flow in phase $\mathrm{C}$ in case of a high $\mathrm{PV}$ production. When the extra flexibility is added by the two three-phase balancing EV chargers and the two three-phase balancing PV inverters, the reverse power flow in phase $\mathrm{C}$ can be diminished by balancing the three phases. This will result in a higher reverse power flow in phase A and B. The more equal division of the load will reduce the system losses and the voltage rise in phase $\mathrm{C}$. This figure also shows that a manual redistribution across the three phases would not be a suitable solution. The highest reverse power flow occurs in phase $\mathrm{C}$, however reconnecting some of these customers to phase A or B would increase the load peaks in the evening in these phases. The consumption in the evening is already higher in phase A and B than in phase C.

In a second simulation, one summer month is evaluated. Fig. 4 presents the voltages in each node for the simulated period. In this figure a modified box plot [49] is applied. An additional box, spanning the 5th to 95th percentiles, is added to the standard box plot. As expected, the classic coordinated charging avoids a violation of the lower voltage
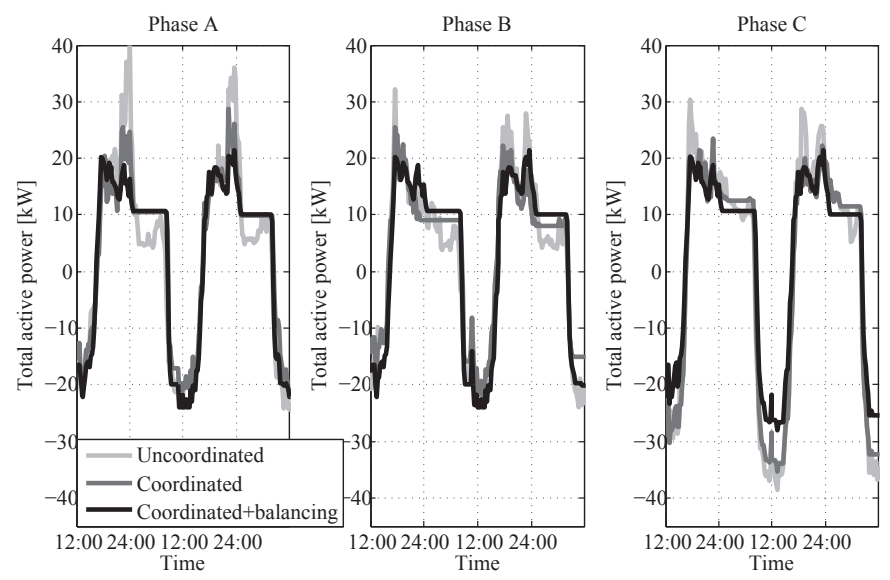

Fig. 3: Total active power in each phase in case of classic coordinated charging and coordinated charging with balancers

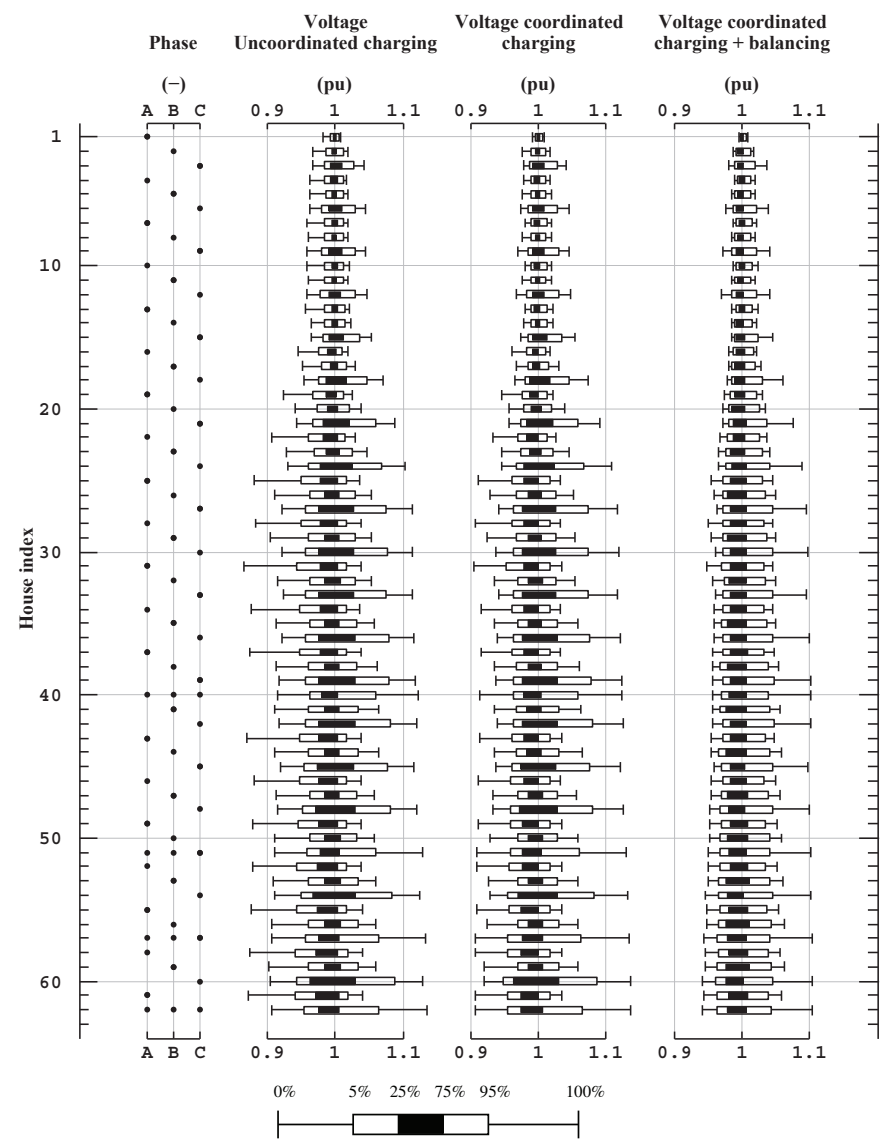

Fig. 4: Modified boxplot of the node voltages for centralized charging strategies

limit. However, it fails to avoid excessive high voltages that occur during time periods of high PV production due to the mismatch between PV production and the energy required by the EVs. When the two three-phase EV chargers and the two three-phase PV inverters can balance the network, the coordinated charging can avoid these excessive voltages.

There are many practical concerns when implementing a coordinated charging strategy. For example, in many EV 
charging algorithms [23], [41], [42], [44], [50], the arrival time and charging demand of each EV was assumed to be known in advance, before the arrival of the EV. Besides that, perfect predictions of the household load and PV production are assumed to be available by most algorithms. However, in reality estimates of these parameters will have to be used. In [50] a coordinated charging strategy was extended to cope with this problem. Another disadvantage of the coordinated charging algorithm is the need for a real-time communication channel and the high computational power. Privacy barriers and technical constraints can make this gathering of information unrealistic. Privacy sensitive information, such as the departure time, is preferably not communicated to a central instance. Communicating privacy sensitive information can be avoided by applying distributed algorithms [44], [51]. However, these methods still rely on real-time communication. In this work it was assumed that the coordinated charging algorithm had perfect predictions in the previous simulations concerning EV behavior, load profiles and PV production. Therefore the results of the simulations are a benchmark solution that indicates what is maximally possible with the balancing inverters.

\section{LOCAL CHARGING OF EVS WITH LOAD BALANCING BY PV INVERTERS AND EV CHARGERS}

The need for a communication infrastructure and the high computational burden are serious disadvantages of the coordinated charging strategy. Therefore a simple and purely local control approach is implemented, which does not rely on any form of communication or load predictions. The application of the local control of the EVs and PV panels will however lead to a suboptimal solution which will be compared with the benchmark of the coordinated charging algorithm.

\section{A. Local control of a balancing EV charger}

For the local control of each off board balancing EV charger, only the absolute values of the local voltage measurements are used. No information about the grid is needed. Phases with a lower voltage have a higher active power consumption due to the voltage drop over the mainly resistive distribution cables. Therefore it is interesting to absorb more power out of the phases with the highest voltage. This is translated in the following droop relationship:

$$
\begin{aligned}
& \left(P_{A}-P_{B}\right)=\gamma\left(\left|V_{A}\right|-\left|V_{B}\right|\right) \\
& \left(P_{A}-P_{C}\right)=\gamma\left(\left|V_{A}\right|-\left|V_{C}\right|\right) \\
& \left(P_{B}-P_{C}\right)=\gamma\left(\left|V_{B}\right|-\left|V_{C}\right|\right) \\
& \left(P_{A}+P_{B}+P_{C}\right)=P^{\mathrm{EV}}
\end{aligned}
$$

\section{Where}

- $\left|V_{A}\right|$ is the absolute value of the voltage of phase A;

- $\left|V_{B}\right|$ is the absolute value of the voltage of phase $\mathrm{B}$;

- $\left|V_{C}\right|$ is the absolute value of the voltage of phase $\mathrm{C}$;

- $\gamma$ is a parameter controlling the inter-phase power delivery $\left[\frac{W}{V}\right]$;
If the magnitude of the voltage in one phase is higher than in another phase, the power difference between the phases is equal to the voltage difference between the phases multiplied by the constant $\gamma$. For example a constant $\gamma$ of $100 \frac{\mathrm{W}}{V}$ will result in a power difference between the two phases of $100 \mathrm{~W}$ per Volt. This makes inter-phase balancing possible. $\gamma$ can therefore be interpreted as a three-phase droop constant.

The charging power set point of an $\mathrm{EV} P^{\mathrm{EV}}$ is equal to the minimum power that is needed to fully charge the EV battery during the time before departure. It is defined by dividing the required amount of energy by the available time period. This type of charging will be called EV-based peak-shaving. This simple method of charging improves grid conditions significantly compared to uncoordinated charging [30].

Eq. (7) can be rewritten as:

$$
\begin{aligned}
& P_{A}=\frac{P^{\mathrm{EV}}+\gamma\left(\left|V_{A}\right|-\left|V_{B}\right|\right)+\gamma\left(\left|V_{A}\right|-\left|V_{C}\right|\right)}{3} \\
& P_{B}=P_{A}-\gamma\left(\left|V_{A}\right|-\left|V_{B}\right|\right) \\
& P_{C}=P_{A}-\gamma\left(\left|V_{A}\right|-\left|V_{C}\right|\right)
\end{aligned}
$$

These formulations do not take into account the constraints of the inverter. Each of the single-phase inverters has a maximum power throughput of $\frac{P_{n}^{\mathrm{EV}} \text {,max }}{3}$, which defines a feasible set for the powers of each inverter. To comply with these constraints, the powers obtained by equation (8) are projected on the feasible set:

$$
\begin{aligned}
& \min _{P^{*}}\left\|P_{A, B, C}^{*}-P_{A, B, C}\right\|_{2}^{2} \\
& \text { subject to } \\
& -\frac{P_{n}^{\mathrm{EV}, \max }}{3} \leq P_{A, B, C}^{*} \leq \frac{P_{n}^{\mathrm{EV}, \max }}{3} \\
& \left(P_{A}^{*}+P_{B}^{*}+P_{C}^{*}\right)=P^{\mathrm{EV}}
\end{aligned}
$$

Where

- $P_{A, B, C}$ is a vector containing the solution obtained by (8)

- $P_{A, B, C}^{*}$ is the projection on the feasible set. The three obtained values are the setpoints for the power injection/absorption in each phase.

The first constraint guarantees that the nominal power of each of the three single-phase chargers is not exceeded and the second ensures that the total power exchanged with the grid is equal to the power requested by the EV chargers. If the operating point obtained by (8) was already part of the feasible set, then (9) does not change the operating point.

Fig. 5 illustrates the operation of the local controller during a partly cloudy day in spring. It depicts the power in each of the three phases of the charger, in this case allocated in node 57, as well as the voltage in node 57 for a $\gamma$ equal to $250 \frac{\mathrm{W}}{\mathrm{V}}$. The sum of the powers in each phase is always equal to the EV charging power. As previously discussed, the charging power is defined as the minimum power that is needed to get the EV battery fully charged during the time before departure. When the EV is absent, the sum of the powers equals zero. The charger tries to balance the grid. It is clear from this figure that during the day, when there is a higher voltage in phase $\mathrm{C}$ due 

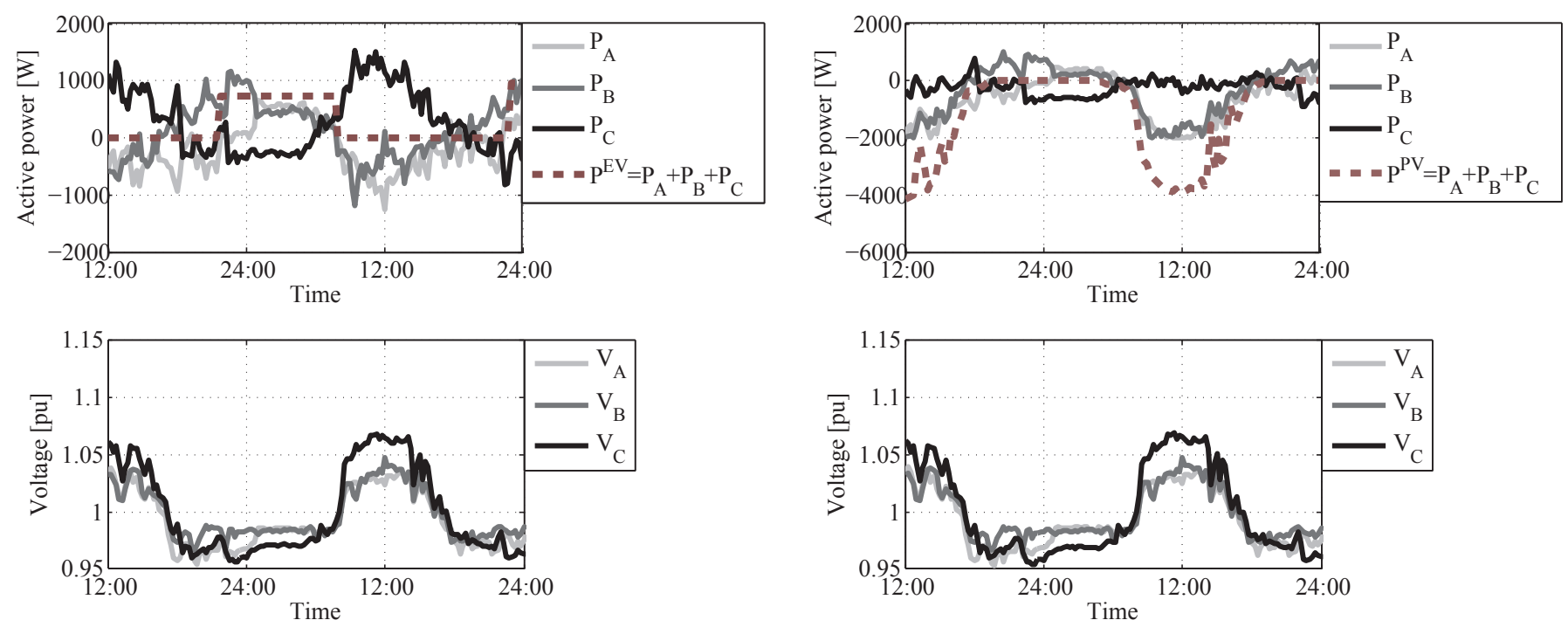

Fig. 5: Power of the balancing EV charger as a function of the grid voltage in node 57.

to a higher PV production in this phase, power is consumed in phase $\mathrm{C}$ by the charger, while it injects this power back into the other phases. When the EV needs to charge, the majority of the energy is extracted from the phase with the highest voltage.

\section{B. Local control of a balancing PV inverter}

The local control of the balancing PV inverters resembles the one of the EV chargers (7). The sum of the power exchanges in each phase with the network equals the total produced power $P^{\mathrm{PV}}$ :

$$
\begin{aligned}
& \left(P_{A}-P_{B}\right)=\gamma\left(\left|V_{A}\right|-\left|V_{B}\right|\right) \\
& \left(P_{A}-P_{C}\right)=\gamma\left(\left|V_{A}\right|-\left|V_{C}\right|\right) \\
& \left(P_{B}-P_{C}\right)=\gamma\left(\left|V_{B}\right|-\left|V_{C}\right|\right) \\
& \left(P_{A}+P_{B}+P_{C}\right)=P^{\mathrm{PV}}
\end{aligned}
$$

The local control rule of the PV is obtained as in (8). If there are regulation limits for the difference in power levels injected between the phases [35], then such requirements can be added to optimization problem (9).

Fig. 6 illustrates the operation of the local controller for a balancing PV inverter in node 62 . As can be seen, the majority of the produced power during the day will be injected in phases $\mathrm{A}$ and $\mathrm{B}$. The voltage in these phases indicates a smaller reverse power flow in these phases. At night power is injected into phase $\mathrm{C}$, which has the lowest voltage. The lower voltage in phase $\mathrm{C}$ indicates a higher consumption in this phase. Since the power production by the PV panel is zero at night, the power injected into phase $\mathrm{C}$ needs to be extracted from the two other phases. These cases are numerical examples of the working of the balancing inverter presented in Fig. 1.

The total active power in each of the three phases for the same two days during summer of Fig. 3 are now shown for the EV based peak shaving with and without the balancing in Fig. 7. A negative value indicates a reverse power flow.

Fig. 6: Power of the balancing PV inverter as a function of the grid voltage in node 62 .
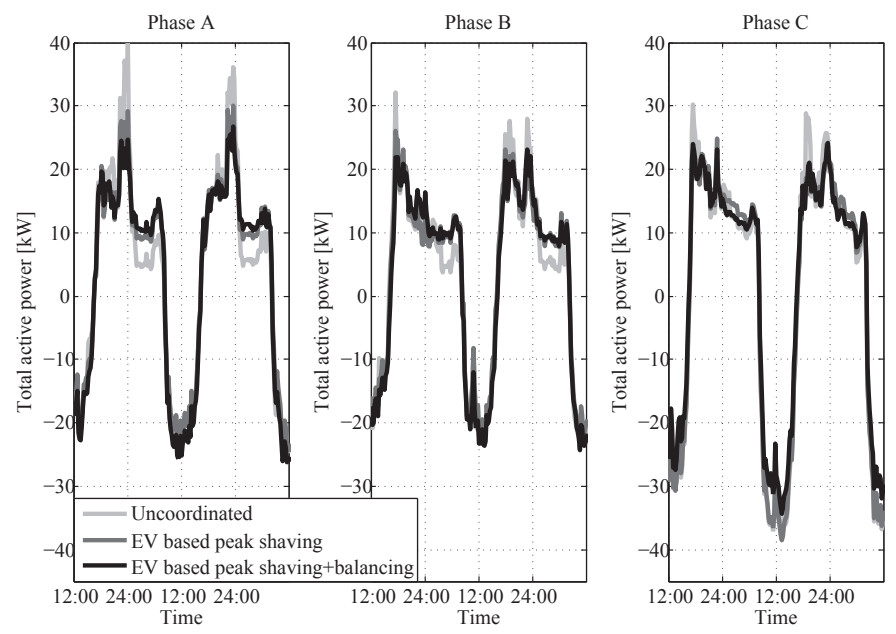

Fig. 7: Total active power in each phase in case of EV based peak shaving and EV based peak shaving with balancers.

The $\gamma$ is chosen to be $250 \frac{W}{V}$. When the two three-phase EV chargers and two PV inverters balance the grid, load peaks are diminished. This has positive effects on the grid voltage. Fig. 8 presents the voltages in each node for the same simulated period as Fig. 4. Due to the balancing, the voltages become closer to the nominal voltage. Moreover, when comparing Fig. 4 and Fig. 8, it is clear that a simple local control approach with two balancing chargers and two balancing inverters outperforms a classic central coordinated charging strategy without the possibility to balance the grid.

Node 62 is an end node and is therefore more vulnerable for voltage problems and severe voltage unbalance. Fig. 9 compares the Voltage Unbalance Factor (VUF) occurring in this node for the different control strategies. According to the European standard, the VUF is defined as the magnitude of the ratio of the negative sequence voltage to the positive sequence voltage [52]. The Cumulative Distribution Function 


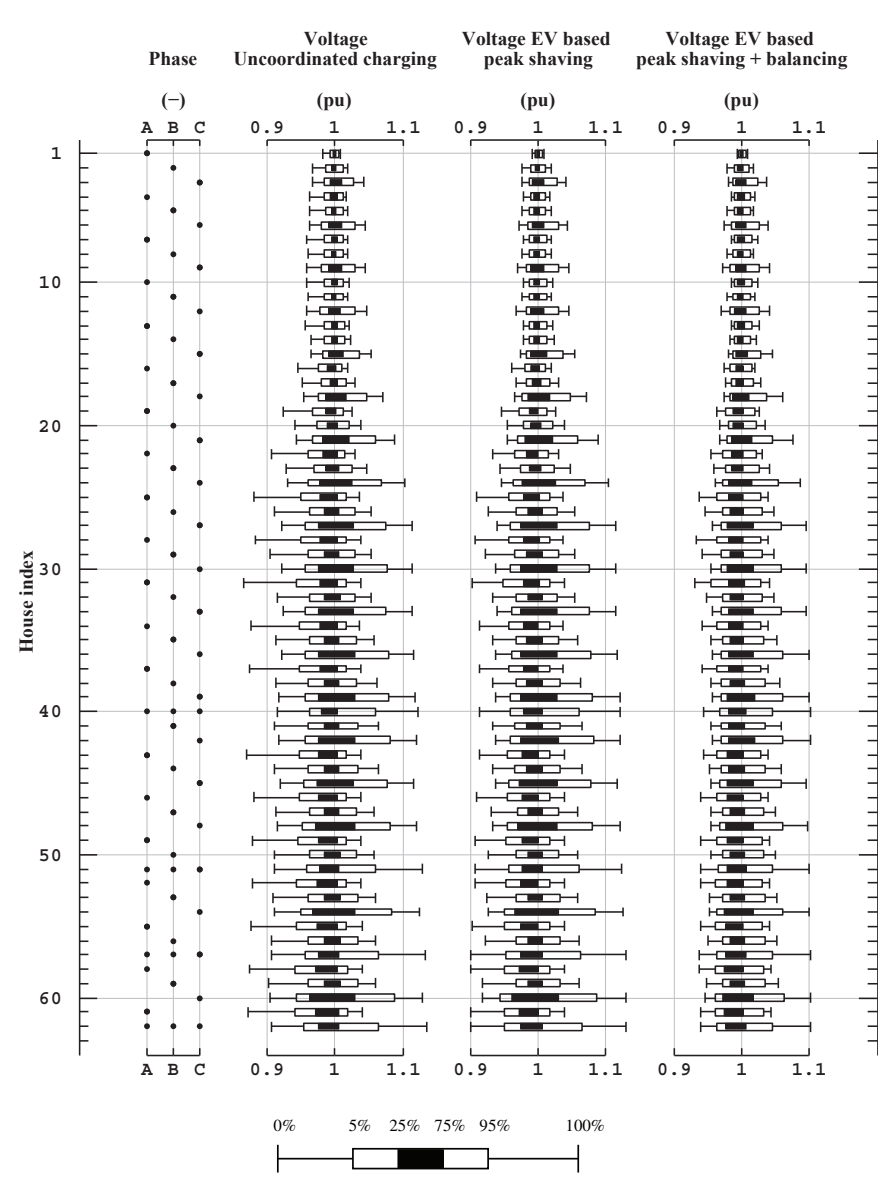

Fig. 8: Modified boxplot of the node voltages for local charging strategies.

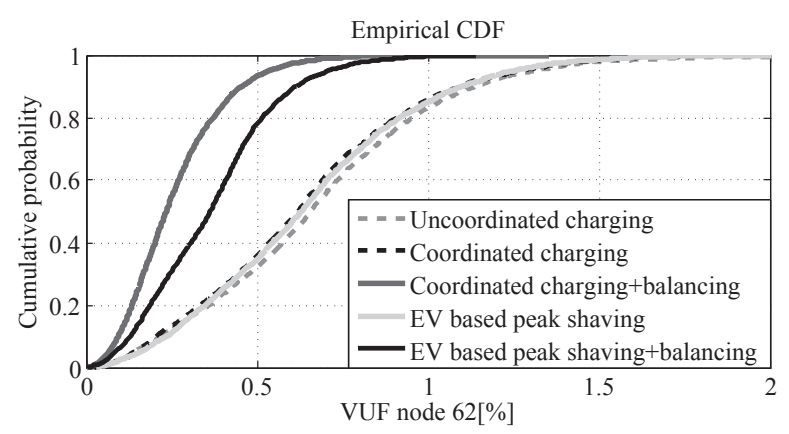

Fig. 9: Cumulative distribution function of the voltage unbalance factor in node 62 .

(CDF) of the VUF is presented for a simulated period of one summer month. The improvements with balancing are clear. Also when there is no PV production or EV available, the balancers further improve the grid conditions, which explains the significant improvement. An increasing amount of EVs and PVs typically worsens the voltage unbalance [1], but by promoting the installation of balancing chargers and inverters the voltage unbalance will be improved compared to the situation without EVs or PVs.

A final constraint that can limit a further integration of EVs and PV panels in the distribution grid are the transformer and

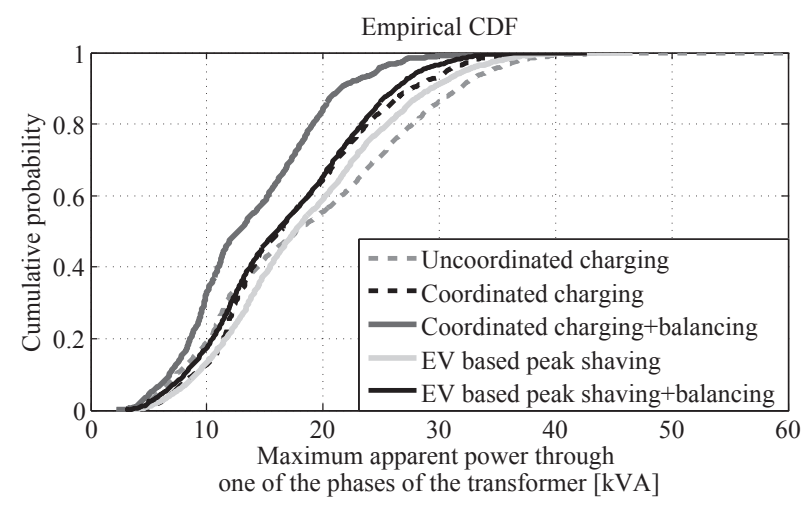

Fig. 10: Cumulative distribution function of the maximum apparent power through one of the phases of the transformer.

TABLE II: Reduction of grid losses compared to uncoordinated charging.

\begin{tabular}{c|c} 
Charging strategy & Reduction [\%] \\
\hline Classic coordinated charging & 16 \\
Coordinated charging + balancing & 28 \\
EV based peak shaving & 7 \\
EV based peak shaving + balancing & 19
\end{tabular}

line loading limits. The CDF of the maximum apparent power through the three phases of the transformer is plotted in Fig. 10. It is clear that when the grid is equipped with balancers the peak loading reduces. The installation of these balancers is therefore beneficial for the lifetime of the transformer.

The balanced grid operation is also beneficial for the grid losses, as these increase with the square of the line currents. Table II compares the possible reduction of grid losses compared to uncoordinated charging. Again the simple local EV based peak shaving with balancing chargers and inverters outperforms the classic coordinated charging problem without balancing.

The benefit of the proposed balancing strategy is therefore that it has a positive effect on both component loading, voltage unbalance, grid voltages and grid losses. Other control strategies often fail to improve all of these indicators. I.e. reactive power control by PV inverters can significantly improve the grid voltages, but might increase the component loading and the grid losses [25], [53].

The location of the inverters balancing the grid influences the effectiveness of the proposed method. Grid unbalance is always more severe at the end of the feeder [1], therefore the further the balancing inverter is located from the substation, the higher the expected improvement. Further research involves the optimal placement of balancing inverters and the development of a prototype.

\section{CONClusion}

The grid impact of the increasing amount of EV charging and PV production can be substantially reduced if they would be able to balance the grid. Both off board three-phase EV chargers and three-phase PV units can be adapted to balance a three-phase four-wire distribution grid. Grid conditions 
will be improved by absorbing power from a phase with a lower loading and injecting this power into the phase with the highest loading. A centralized coordinated EV charging problem is adapted in this work to evaluate the effects of the extra flexibility added by these balancers. Several load flow simulations with realistic data are performed and show a significant improvement of both component loading, voltage unbalance, grid voltages and grid losses when some threephase chargers and PV-units are adapted to balance the grid. Thanks to these units, more PVs and EVs could be connected to the distribution network, before critical limits are reached.

Even with a simple local control rule, two off board EV chargers and two PV inverters that are able to balance the grid, will improve the grid conditions more than a computationally and communicationally intensive classic coordinated EV charging strategy. An affordable implementation of these types of balancers can therefore become a cost-effective option for DSOs to cope with the increasing amount of EVs and PV panels.

\section{ACKNOWLEDGEMENT}

The authors would like to thank J. Tant and C. Gonzalez for the discussions concerning unbalanced distribution grids and N. Fieremans for the thorough review of this work.

\section{REFERENCES}

[1] F. Shahnia, R. Majumder, A. Ghosh, G. Ledwich, and F. Zare, "Sensitivity analysis of voltage imbalance in distribution networks with rooftop PVs," in Proc. IEEE Power and Energy Society General Meeting, 2010, pp. 1-8.

[2] M. Elnozahy and M. Salama, "A comprehensive study of the impacts of PHEVs on residential distribution networks," IEEE Trans. Sust. Energy, vol. 5, no. 1, pp. 332-342, Jan 2014.

[3] F. Shahnia, A. Ghosh, G. Ledwich, and F. Zare, "Voltage unbalance sensitivity analysis of plug-in electric vehicles in distribution networks," in Universities Power Engineering Conf. (AUPEC), 2011 21st Australasian, Sept 2011, pp. 1-6.

[4] M. Gray and W. Morsi, "Power quality assessment in distribution systems embedded with plug-in hybrid and battery electric vehicles," IEEE Trans. Power Syst., vol. PP, no. 99, pp. 1-9, 2014.

[5] R. Yan and T. Saha, "Investigation of voltage sensitivities to photovoltaic power fluctuations in unbalanced distribution networks," in Power and Energy Society General Meeting, 2012 IEEE, July 2012, pp. 1-7.

[6] H. Pezeshki, P. Wolfs, and G. Ledwich, "Impact of high PV penetration on distribution transformer insulation life," IEEE Trans. Power Del., vol. 29, no. 3, pp. 1212-1220, June 2014.

[7] S. Weckx, C. GonzalezDeMiguel, P. Vingerhoets, and J. Driesen, "Phase switching and phase balancing to cope with a massive photovoltaic penetration," in Electricity Distribution (CIRED 2013), 22nd Int. Conf. and Exhibition on. IET, 2013, pp. 1-4.

[8] F. Shahnia, P. Wolfs, and A. Ghosh, "Voltage unbalance reduction in low voltage feeders by dynamic switching of residential customers among three phases," IEEE Trans. Smart Grid, vol. 5, no. 3, pp. 1318-1327, May 2014.

[9] W. M. Siti, A. Jimoh, and D. Nicolae, "Distribution network phase load balancing as a combinatorial optimization problem using fuzzy logic and newton raphson," Electric Power Systems Research, vol. 81, no. 5, pp. 1079 - 1087, 2011. [Online]. Available: http://www.sciencedirect.com/science/article/pii/S0378779610003299

[10] P.-T. Cheng, C.-A. Chen, T.-L. Lee, and S.-Y. Kuo, "A cooperative imbalance compensation method for distributed-generation interface converters," IEEE Trans. Ind. Applications, , vol. 45, no. 2, pp. $805-815$, march-april 2009.

[11] F. Wang, J. Duarte, and M. Hendrix, "Control of grid-interfacing inverters with integrated voltage unbalance correction," in IEEE Power Electronics Specialists Conf., PESC, june 2008, pp. 310 -316.
[12] B. Meersman, B. Renders, L. Degroote, T. Vandoorn, and L. Vandevelde, "Three-phase inverter-connected DG-units and voltage unbalance," Electric Power Systems Research, vol. 81, no. 4, pp. 899 - 906, 2011.

[13] H. Patel and V. Agarwal, "PV based distributed generation with compensation feature under unbalanced and non-linear load conditions for a 3-phase, 4-wire system," in 2006. ICIT 2006. IEEE Int. Conf. Ind. Technology, on, dec. 2006, pp. $322-327$.

[14] H. Beltran, Z. Chen, E. Belenguer, N. Aparicio, S. SeguiChilet, and F. Gimeno-Sales, "Photovoltaic inverters used as active filters for improvement of LV distribution networks," in Electric Utility Deregulation and Restructuring and Power Technologies, 2008. DRPT 2008. 3rd Int. Conf. on, 2008, pp. 2749-2756.

[15] R. Caldon, M. Coppo, and R. Turri, "Distributed voltage control strategy for LV networks with inverter-interfaced generators," Electric Power Systems Research, vol. 107, no. 0, pp. 85 - 92, 2014.

[16] M. Falahi, H.-M. Chou, M. Ehsani, L. Xie, and K. Butler-Purry, "Potential power quality benefits of electric vehicles," IEEE Trans. Sust. Energy, vol. 4, no. 4, pp. 1016-1023, Oct 2013.

[17] S. Weckx, R. D’Hulst, B. Claessens, and J. Driesen, "Multiagent charging of electric vehicles respecting distribution transformer loading and voltage limits," IEEE Trans. Smart Grid,, vol. 5, no. 6, pp. 28572867, 2014

[18] J. Van Roy, N. Leemput, F. Geth, R. Salenbien, J. Buscher, and J. Driesen, "Apartment building electricity system impact of operational electric vehicle charging strategies," IEEE Trans. Sust. Energy, vol. 5, no. 1, pp. 264-272, Jan 2014.

[19] F. Marra, G. Yang, Y. Fawzy, C. Traeholt, E. Larsen, R. Garcia-Valle, and M. Jensen, "Improvement of local voltage in feeders with photovoltaic using electric vehicles," IEEE Trans. Power Syst., vol. 28, no. 3, pp. 3515-3516, Aug 2013.

[20] J. de Hoog, T. Alpcan, M. Brazil, D. Thomas, and I. Mareels, "Optimal charging of electric vehicles taking distribution network constraints into account," IEEE Trans. Power Syst., vol. PP, no. 99, pp. 1-11, 2014.

[21] A. O'Connell, D. Flynn, and A. Keane, "Rolling multi-period optimization to control electric vehicle charging in distribution networks," IEEE Trans. Power Syst., vol. 29, no. 1, pp. 340-348, Jan 2014.

[22] M. Singh, I. Kar, and P. Kumar, "Influence of EV on grid power quality and optimizing the charging schedule to mitigate voltage imbalance and reduce power loss," in Power Electronics and Motion Control Conf. (EPE/PEMC), 2010 14th Int., Sept 2010, pp. T2-196-T2-203.

[23] K. Clement-Nyns, E. Haesen, and J. Driesen, "The impact of charging plug-in hybrid electric vehicles on a residential distribution grid," IEEE Trans. Power Syst., vol. 25, no. 1, pp. 371-380, Feb 2010.

[24] X. Su, M. Masoum, and P. Wolfs, "Optimal PV inverter reactive power control and real power curtailment to improve performance of unbalanced four-wire lv distribution networks," IEEE Trans. Sust. Energy, vol. 5, no. 3, pp. 967-977, July 2014.

[25] S. Weckx, C. Gonzalez, and J. Driesen, "Combined central and local active and reactive power control of PV inverters," IEEE Trans. Sust. Energy, vol. 5, no. 3, pp. 776-784, July 2014.

[26] A. Bonfiglio, M. Brignone, F. Delfino, and R. Procopio, "Optimal control and operation of grid-connected photovoltaic production units for voltage support in medium-voltage networks," IEEE Trans. Sust. Energy, vol. 5, no. 1, pp. 254-263, Jan 2014.

[27] R. Tonkoski, L. A. C. Lopes, and T. H. M. EL-Fouly, "Coordinated active power curtailment of grid connected PV inverters for overvoltage prevention," IEEE Trans. Sust. Energy, vol. 2, no. 2, pp. 139-147, April 2011.

[28] Y. Ueda, K. Kurokawa, T. Tanabe, K. Kitamura, and H. Sugihara, "Analysis results of output power loss due to the grid voltage rise in grid-connected photovoltaic power generation systems," IEEE Trans. Ind. Elec., vol. 55, no. 7, pp. 2744-2751, July 2008.

[29] E. Demirok, D. Sera, R. Teodorescu, P. Rodriguez, and U. Borup, "Clustered PV inverters in LV networks: An overview of impacts and comparison of voltage control strategies," in Electrical Power Energy Conf. (EPEC), 2009 IEEE, oct. 2009, pp. 1 -6.

[30] N. Leemput, F. Geth, J. Van Roy, A. Delnooz, J. Buscher, and J. Driesen, "Impact of electric vehicle on-board single-phase charging strategies on a flemish residential grid," IEEE Trans. Smart Grid, vol. 5, no. 4, pp. 1815-1822, July 2014.

[31] P. Ferreira, P. M. S. Carvalho, L. A. F. M. Ferreira, and M. Ilic, "Distributed energy resources integration challenges in low-voltage networks: Voltage control limitations and risk of cascading," IEEE Trans. Sust. Energy, vol. 4, no. 1, pp. 82-88, Jan 2013.

[32] F. Marra, G. Yang, C. Traeholt, E. Larsen, J. Ostergaard, B. Blazic, and W. Deprez, "EV charging facilities and their application in LV feeders 
with photovoltaics," IEEE Trans. Smart Grid, vol. 4, no. 3, pp. 1533 1540, Sept 2013.

[33] S. Hashemi, J. Ostergaard, and G. Yang, "A scenario-based approach for energy storage capacity determination in LV grids with high PV penetration," IEEE Trans. Smart Grid, vol. 5, no. 3, pp. 1514-1522, May 2014

[34] B. Rotthier, T. Van Maerhem, P. Blockx, P. Van den Bossche, and J. Cappelle, "Home charging of electric vehicles in Belgium," in Electric Vehicle Symposium and Exhibition (EVS27), 2013 World, Nov 2013, pp. $1-6$.

[35] Synergrid, "Specifieke technische voorschriften voor decentrale productie- installaties die in parallel werken met het distributienet, synergrid regulation c10/11," Federatie van de netbeheerders elektriciteit en aardgas in Belgi, Tech. Rep., 2012.

[36] S. Weckx, C. GonzalezDeMiguel, and J. Driesen, "Reducing grid losses and voltage unbalance with PV inverters," in Power and Energy Society General Meeting, 2014 IEEE, July 2014, pp. 1-5.

[37] Kabels Voor Ondergrondse Aanleg, met Synthetische Isolatie en Versterkte Mantel (Type 1kV), NBN Std. C 33-322, 1975 Std.

[38] W. Labeeuw and G. Deconinck, "Residential electrical load model based on mixture model clustering and markov models," IEEE Trans. Ind. Inform., vol. 9, no. 3, pp. 1561-1569, 2013.

[39] J. Van Roy, N. Leemput, S. De Breucker, F. Geth, P. Tant, and J. Driesen, "An Availability Analysis and Energy Consumption Model for a Flemish Fleet of Electric Vehicles," in European Electric Vehicle Congr. (EEVC), Brussels, Belgium, October 26-28, 2011.

[40] C. Cheng and D. Shirmohammadi, "A three-phase power flow method for real-time distribution system analysis," IEEE Trans. Power Syst., vol. 10, no. 2, pp. $671-679$, may 1995.

[41] E. Sortomme, M. M. Hindi, S. D. J. MacPherson, and S. S. Venkata, "Coordinated charging of plug-in hybrid electric vehicles to minimize distribution system losses," IEEE Trans. Smart Grid, vol. 2, no. 1, pp. 198-205, 2011.

[42] Z. Ma, D. Callaway, and I. Hiskens, "Decentralized charging control of large populations of plug-in electric vehicles," IEEE Trans. Control Syst. Tech., vol. 21, no. 1, pp. 67-78, Jan 2013.

[43] L. Jian, H. Xue, G. Xu, X. Zhu, D. Zhao, and Z. Shao, "Regulated charging of plug-in hybrid electric vehicles for minimizing load variance in household smart microgrid," IEEE Trans. Ind. Electr., vol. 60, no. 8, pp. 3218-3226, Aug 2013.

[44] L. Gan, U. Topcu, and S. Low, "Optimal decentralized protocol for electric vehicle charging," IEEE Trans. Power Syst., vol. 28, no. 2, pp. 940-951, May 2013.

[45] S. Boyd and L. Vandenberghe, Convex Optimization. Cambridge University Press, Mar. 2004.

[46] "IBM ILOG CPLEX Optimizer," http://www01.ibm.com/software/integration/optimization/cplex-optimizer/, 2014.

[47] L. Degroote, B. Renders, B. Meersman, and L. Vandevelde, "Neutralpoint shifting and voltage unbalance due to single-phase DG units in low voltage distribution networks," in Proc. IEEE Bucharest PowerTech, 2009 , pp. $1-8$.

[48] C. Gonzalez, J. Geuns, S. Weckx, T. Wijnhoven, P. Vingerhoets, T. De Rybel, and J. Driesen, "LV distribution network feeders in Belgium and power quality issues due to increasing PV penetration levels," in Innovative Smart Grid Technologies (ISGT Europe), 2012 3rd IEEE PES Int. Conf. and Exhibition on, Oct 2012, pp. 1-8.

[49] J. Tant, F. Geth, D. Six, P. Tant, and J. Driesen, "Multiobjective battery storage to improve PV integration in residential distribution grids," IEEE Trans. Sust. Energy, vol. 4, no. 1, pp. 182 -191, jan. 2013.

[50] W. Tang, S. Bi, and Y. Zhang, "Online coordinated charging decision algorithm for electric vehicles without future information," IEEE Trans. Smart Grid, vol. 5, no. 6, pp. 2810-2824, Nov 2014.

[51] M. Kraning, E. Chu, J. Lavaei, and S. Boyd, "Dynamic network energy management via proximal message passing," Foundations and Trends in Optimization, vol. 1, no. 2, pp. 73-126, 2014.

[52] A. von Jouanne and B. Banerjee, "Assessment of voltage unbalance," IEEE Trans. Power Del., vol. 16, no. 4, pp. 782-790, Oct 2001.

[53] T. Stetz, F. Marten, and M. Braun, "Improved low voltage gridintegration of photovoltaic systems in Germany," IEEE Trans. Sust. Energy, vol. 4, no. 2, pp. 534-542, 2013.

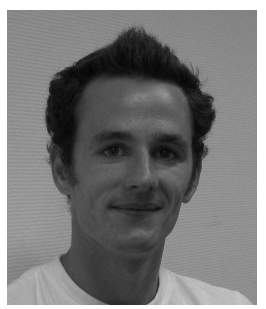

\section{BIOGRAPHIES}

Sam Weckx (S'11) received the M.Sc. degree in Electrical Engineering in 2009 and Mechanical Engineering in 2010 from the Katholieke Universiteit Leuven (KU Leuven), Belgium, where he is currently working towards the Ph.D. degree as a research assistant with the division ESAT-ELECTA. His research interests include the application of distributed optimization in smart grids and voltage control in distribution networks.

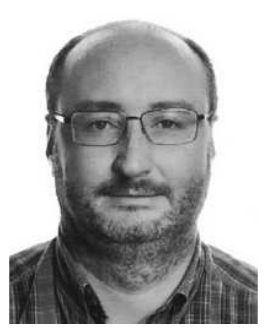

Johan Driesen (S'93 - M'97 - SM'12) received the M.Sc. and Ph.D. degrees in Electrical Engineering from the Katholieke Universiteit Leuven (KU Leuven), Leuven, Belgium, in 1996 and 2000, respectively. Currently, he is a Professor with the KU Leuven and teaches power electronics and electric drives. In 2000, he was with the Imperial College of Science, Technology and Medicine, London, U.K. In 2002, he was with the University of California, Berkeley. Currently, he conducts research on distributed generation, power electronics, and its

applications. 